\title{
The Worldview of Malay Youths in the Virtual World of Second Life: The Real-World Escapism
}

\section{Norhayati Mohd Yusof, Wan Nor Jazmina Wan Ariffin}

To Link this Article: http://dx.doi.org/10.6007/IJARBSS/v11-i3/8595

DOI:10.6007/IJARBSS/v11-i3/8595

Received: 01 January 2021, Revised: 26 January 2021, Accepted: 18 February 2021

Published Online: 14 March 2021

In-Text Citation: (Yusof \& Ariffin, 2021)

To Cite this Article: Yusof, Norhayati M., \& Ariffin, W. N. J. W. (2021). The Worldview of Malay Youths in the Virtual World of Second Life: The Real-World Escapism. International Journal of Academic Research in Business and Social Sciences, 11(3), 700-707.

Copyright: (c) 2021 The Author(s)

Published by Human Resource Management Academic Research Society (www.hrmars.com)

This article is published under the Creative Commons Attribution (CC BY 4.0) license. Anyone may reproduce, distribute, translate and create derivative works of this article (for both commercial and non-commercial purposes), subject to full attribution to the original publication and authors. The full terms of this license may be seen at: http://creativecommons.org/licences/by/4.0/legalcode

Vol. 11, No. 3, 2021, Pg. 700 - 707

Full Terms \& Conditions of access and use can be found at http://hrmars.com/index.php/pages/detail/publication-ethics 


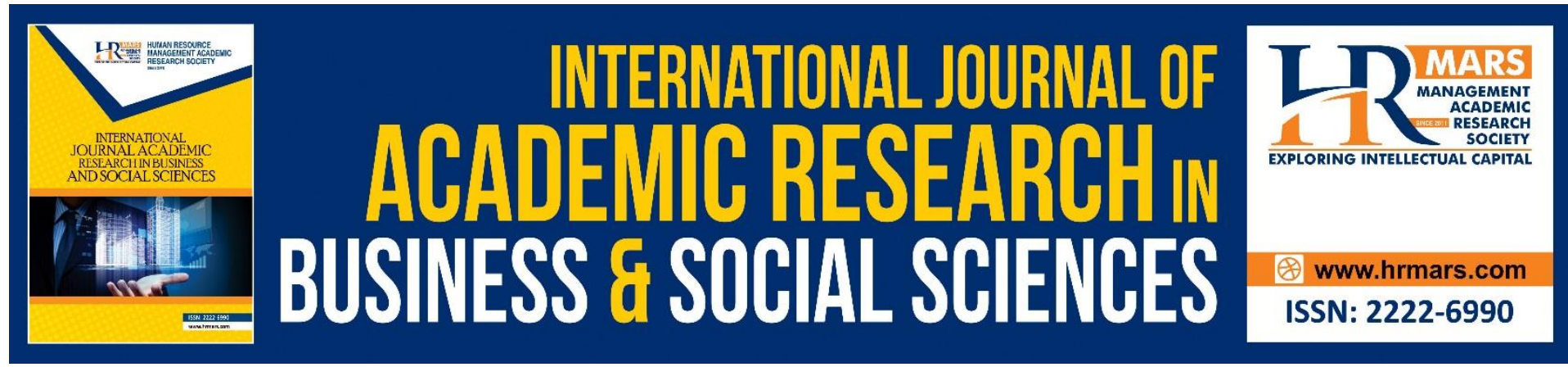

\title{
The Worldview of Malay Youths in the Virtual World of Second Life: The Real-World Escapism
}

\author{
Norhayati Mohd Yusof ${ }^{1}$, Wan Nor Jazmina Wan Ariffin² \\ ${ }^{1}$ Faculty of Education, Universiti Teknologi MARA Cawangan Selangor, Kampus Puncak Alam \\ ${ }^{2}$ Fakulti Sains Sosial Gunaan, Universiti Sultan Zainal Abidin \\ Emai: norhayatimy@uitm.edu.my
}

\begin{abstract}
This qualitative study investigated the worldview of a group of Malaysian Malay youths known as SL1Malaysia in the virtual world of Second Life, spanning more than two years from 2012 to the present. Kozinet's model of Netnography within the ethnographic framework was used to describe the online communities or groups in the virtual world, where people are represented by avatars. Data were collected via online interviews with participants selected from the SL1Malaysia group based on two a priori criteria. These participants consisted of six active, closely-knitted, loyal members inhabiting the virtual environment of Second Life. The worldview elements contributing to the real-world escapism were examined through the representation of the participants' senses, thoughts, and actions via their avatars. The participants listed several reasons leading to real-world escapism, such as relief of real-life stress, neglecting real-life responsibilities, and obsession, among others. There is an urgent need for us to further ascertain the influence of the virtual platform on the construction of alternative worldviews among the Malay youths in Malaysia.
\end{abstract}

Keywords: Second Life, Virtual world, Real-World Escapism, Construction of an Alternative Worldview

\section{Introduction}

Second Life is an online platform that Linden Research Incorporated developed in 2003 to allow users to interact and communicate with each other on any topic in a virtual environment. These topics encompass hobbies, fashion, food, business engagement, discussion forums, or simply any activities, inclusive of religion and education as well. Since its establishment in 2003, Second Life grows rapidly. Its new account registrations nearly reached 350,000 monthly in just 15 years, as reported in its 2018 anniversary infographics (Buscemi, 2020). In the virtual environment of Second Life, the users can control, manipulate, and script almost all of the content and journey in the virtual domain, thereby allowing them to create their world based on their imagination, creativity, fantasy, and desires. Besides, users can choose whoever they want to be and do whatever they wish to, without any restriction and inhibition of religious, cultural, moral, or legal sanctions of the real world. In other words, there are no universally binding rules for them (Furber, 2009). 
Most people may think that the virtual world of Second Life is just a game-based environment (Furber, 2009). However, unlike the game-based virtual environment in which users are competing with others or oneself to score certain points to move from one level to another, in the virtual environment of Second Life, there are simply no goals to strive for, no levels to move on, and no points to score (Furber, 2009). In addition, users in the game-based virtual environment are known as players, whereas in Second Life, they are known as residents with the capability of creating their community, and venturing into the virtual environment. These residents can freely interact with others through their personified graphic representation known as "avatar" (Holzwarth et al., 2006 cited by Gadalla, Abosag and Keeling, 2016). Given that these residents are emotionally and personally attached to their avatars, their behaviour and attitudes in the real world can therefore be easily affected (Furber 2009). Thus, the virtual world of Second Life may adversely affect the residents' worldview, which is one's attitudes, philosophy of life, religious belief, as well as perceptions of the world (Funk, 2001). Other attributes such as one's concepts of vision of life, truth as well as one's existence may also be considered as one's worldview (Berghout, 2009).

In the absence of an effective mechanism regulating their limits in the exploration, users would become more and more indulged in this virtual environment, thereby heightening their confusion on their worldview (Kamal, Ismael and Norhayati, 2012). As a result, they would view Second Life as an alternative to real-life, while developing an altered ego, which would be different from their real-life identity (Aboujaoude, 2011).

In Malaysia, the effect of indulging in the virtual world in shaping one's attitudes and behaviours largely remains uninvestigated (Kamal et al., 2012). There is a need for us to ascertain the influence of virtual platforms on the construction of alternative worldviews among the Malay youths in Malaysia as a form of escapism. Based on Funk's thoughts about how we perceive ourselves and our surroundings (Funk, 2001), this study investigated the real-life escapism of a group of Malaysian Malay youths. Specifically, this real-life escapism, manifested in the senses, thoughts, and actions of the Malaysian Malay youths via their avatars in Second Life, was examined using Kozinet's model of Netnography through online fieldworks and interviews (Kozinets, 2010a). The present study may serve as a starting point for further in-depth investigation in Malaysia on the effect of indulging in a virtual environment on the development of an altered ego among the Malaysian Malay youths. An illustration of such acts can be seen in the screen capture in Figure 1.1.

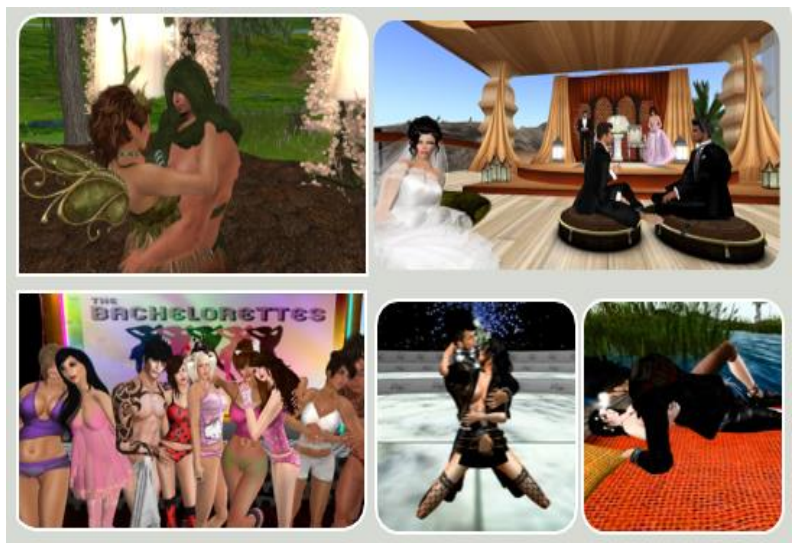

Figure 1.1: Some of the activities created by the SL1Malaysia family members 


\section{Methodology \\ The Study Subjects}

The study subject in this research comprised a group of Second Life residents known as SL1Malaysia in the virtual environment, consisting mostly of the Malays. They used this virtual environment solely for entertainment and socialisation via an altered identity, which differed markedly from their real-life personalities. They manifested their fantasies in the virtual world with an emphasis on sexual attractiveness and masculinity, something which was not allowed in their religions and cultures. However, in real-life, they appeared to be physically normal, tidy-looking and wearing the hijab. Also, there appeared to be a cultish element existing in this SL1Malaysia group. For example, whenever the group leader beckoned an instruction, the members would obsequiously obey, as if nothing else matters.

\section{Approach}

Case-study approach was used in this study to investigate the SL1Malaysia group in the virtual world of Second Life on how they sense, think, and act in their changing worldview. This casestudy approach explores real-life problems, and cases or multiple cases over a specific period with data collection including observations, interviews, audiovisual materials, and documents (Creswell, 2013). The targeted research subject in a case study can be an individual, a small group, an organisation, or a partnership. A case description with the appropriate case themes is then developed. In the present study, the ethnographic framework was used to form the basis of the research design because ethnographies provide a complex and complete description of the cultural sharing of a study group or a subset of a study group (Creswell, 2013).

Following the approach of Kozinets (2010a), the present study used Netnography, which is designed for conducting online fieldwork, to describe the online communities or groups in the virtual world, where people are merely avatars. The present study also adhered to the six steps incorporated in Netnography following the ethnographic research framework (Kozinets, 2010b). These six steps were research planning, entrée, data collection, data analysis, compliance with ethical standards, and research representation and evaluation.

\section{Online fieldwork and data acquisition}

For this study, the researcher befriended the whole group of SL1Malaysia, especially the group leader and his virtual wife by establishing rapports from the year 2012 to the present. The researcher learned their rules and regulations, participated in their activities and daily communication, and adopted their language idiosyncrasies to minimise biases and presumptions.

Meanwhile, the purposive or non-probability sampling was used in this study. A purposive sample consisting of informants was selected from the members of SL1Malaysia residents who were active users of Second Life based on two criteria. These criteria were: they must be loyal members of the SL1Malaysia group, and they must have spent at least eight hours per day in the virtual environment of Second Life. A total of six informants were selected, of which two were the group leader together with his virtual wife. These two group leaders were the most influential and impartial avatars among the members of the SL1Malaysia. Another two informants were the loyal followers who were always there when they were needed especially in organising any events and family activities. The last two informants were the ordinary members who would join a family gathering if they were available, and they were 
not obligated to participate in any particular events or family activities. These six informants were designated as SLM1, SLM2, SLM3, SLM4, SLM5, and SLM6.

Altogether there were six interview sessions conducted for the SL1Malaysia group in the virtual environment, which was located on the online programme of Second Life. The interviews were held using the chatbox as the medium of interaction between the researcher's avatar and the participants' avatars. . Figure 1.2 below shows one situation between the researcher's avatar and one of the respondents' avatar before the interview session started.

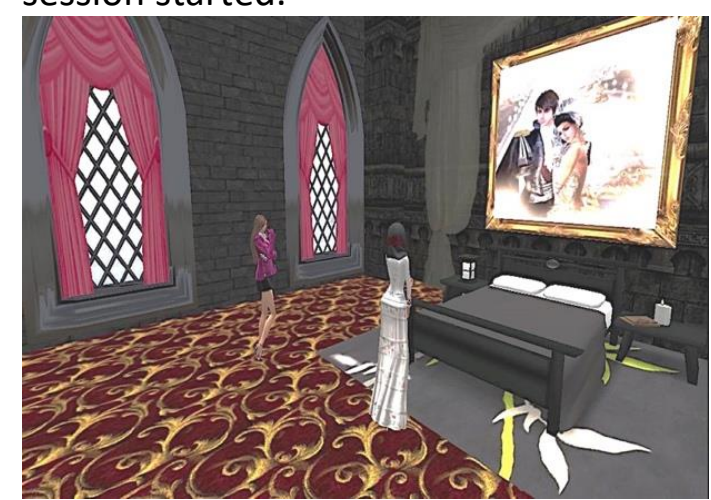

Figure 1.2: Conversation between researchers' avatar with one of the respondents' avatar before the interview session started.

As for data analysis, various techniques such as coding, annotation, abstracting and comparing, and generalising and theorising were employed using manual coding template and ATLAS.ti version 7 in developing main themes and sub-themes based on informants' sensing, thinking, and acting in the virtual environment of Second Life. Overall, the SL1 Malaysia group was examined in their natural cultural setting.

\section{Results and Discussion}

Based on the interviews with the informants, six sub-themes were generated, namely, (1) escaping from reality and ample freedom, (2) fun, (3) relief of real-life stress, (4) addiction, (5) high virtual purchasing power, and (6) neglecting real-life responsibilities. According to the responses of the informants, these sub-themes were the main reasons leading to their reallife escapism.

\section{Escaping from reality and ample freedom}

The online interviews revealed that five informants, namely SLM1, SLM2, SLM3, SLM4, and SLM6, viewed Second Life as a means of escapism from realities while affording them greater freedom to do things as they like without any attachment to real life. One of the informants said,

"Second Life is a world where I am free and able to show my hidden self. It is a world by which I can immerse into other people's world while exploring my creativity" (SLM1: D.U 24).

Clearly, SLM1 expressed her hidden self or her projected self onto the virtual world. Whatever she did in Second Life differed substantially from her real life. It is likely that in her real life she was not able to express her hidden self, due to several parental and religious restrictions. 
Fun

Meanwhile, two informants (SLM2 and SLM4) disclosed that Second Life was a medium for them to have fun. The informant designated as SLM2 explicitly said,

"Second Life is fun actually, but it depends on how the residents defined the word fun. For me, I am having fun when I am designing artifacts" (SLM2:

D.U 176).

SLM2 claimed that she learned the skills of designing artifacts only in Second Life but not in her real life. Thus, she logged in almost every day mainly to enhance her skills in designing artifacts in addition to her other virtual responsibilities towards her virtual husband and virtual family.

\section{Relieving real-life stress}

For the informants SLM2 and SLM6, Second Life was a medium to relieve real-life stress. According to SLM2,

"There are many stressed people around me in real-life, and they can get rid of those tensed feelings by immersing themselves into Second Life" (SLM2: D.U 178).

Implied in the statement is that by having fun with friends in SL and through spending time teleporting to other places, venturing into the programme and doing activities with other SL1Malaysia members they are able to overcome the real-life stress. The illustration below (Figure 1.3) shows one of the family events.

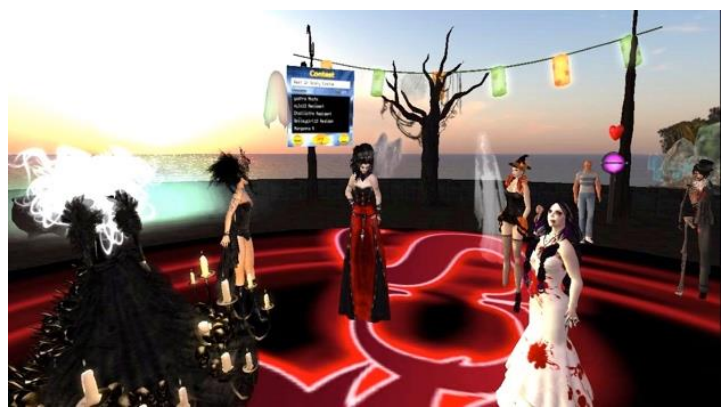

Figure 1.3: Family members of SL1Malaysia gathered at Legion of Redics, Missouri Rivers where SL1Malaysia is located for Halloween Party on Thursday, October 31, 2013 at 10:16am

\section{Addiction}

The interview with SLM1 also revealed that she spent most of her time immersing in Second Life rather than focusing on her real-life responsibilities largely because she felt that Second Life was an addictive virtual programme. She said,

"I am addicted to the Second Life programme. I spend at least two to three days a week at the cybercafe for more than eight hours per day. I cannot focus on my study" (SLM1: D.U 40, 56).

\section{High virtual purchasing power}

According to SLM2, she was able to buy the dress, costumes, accessories, or even a house and land in Second Life, which she could not afford in her real life. She said,

"I used my real-life income and my credit card to buy anything that I want in the Second Life, such as house, land, accessories, and many more. I am a 
rich person in Second Life. Of course in my real-life, I can't afford to buy those things" (SLM2: D.U 38).

SLM2 was able to enjoy a luxurious lifestyle in the virtual world of Second Life.

\section{Neglecting real-life responsibilities}

Based on the interview, SLM4 reveal that whenever the leader of the SL1Malaysia called for a meeting or an event, all the group members attended it regardless of the time and the day. She added,

"Oh yes, as part of the family member, it was my responsibility to attend

all the events or gatherings regardless of the time. I just put aside my real-

life responsibilities to attend the virtual gatherings" (SLM4: D.U 121).

Figure 1.4 shows one of the marriage anniversary celebration events that family members of SL1Malaysia attended.

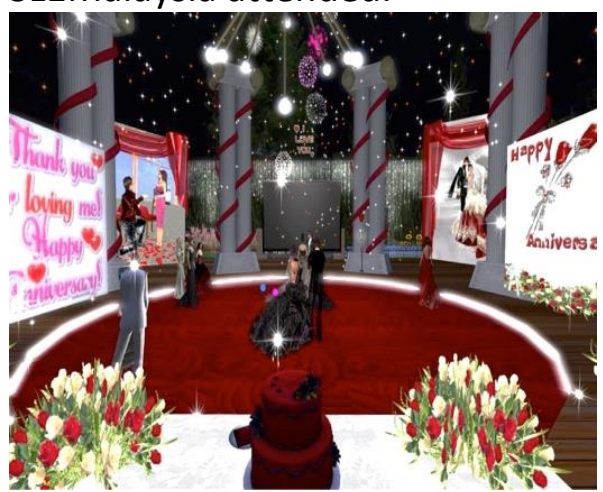

Figure 1.4: SLM2 and SLM6 at their marriage anniversary celebration

\section{Summary and Recommendations}

The findings reveal that the way the respondents' sense, think, and act as avatar in the virtual world of Second Life is one way they escape from the realities of real life. For them Second Life is a world without any restriction like what we have in the real world, based on religion and man-made laws. Apparently, it seems that they are trying to escape from who they are in real life, escape from their real-life responsibilities and stress. Moreover, while indulging oneself in the virtual world of Second Life may afford them ample freedom, high purchasing power and fun which later result in addiction.

The use of Second Life as a tool for the real-world escapism has to be treated with care, otherwise it has potential to adversely impact our worldview. The findings also reflect that there are still a lot to be done in order to create awareness among the Internet surfers especially the 3D virtual world residents, which mostly are the youth.

Hence, there is an urgent need to further ascertain the influence of the virtual platform on the construction of alternative worldviews among the Malay youths in Malaysia. In these alternative worldviews, they tend to escape from their real-life responsibilities while boosting their e-personality that they have developed when immersing in the virtual world of Second Life to the extent that they might not even be able to differentiate the real from the virtual. 


\section{References}

Aboujaoude, E. (2011). Virtually you: The dangerous powers of the e-personality. New York: W.W Norton \& Company Inc.

Berghout, A. (2009). Toward an Islamic framework for worldview studies: Preliminary theorization. The American Journal of Islamic Social Sciences, 24(2), 22-43.

Buscemi, J. (2020). "Second Life" still has dedicated users in 2020. Here's what keeps them sticking around. Retrieved from https://www.mic.com/p/second-life-still-hasdedicated-users-in-2020-heres-what-keeps-them-sticking-around-18693758

Creswell, J. W. (2013). Qualitative inquiry and research design: Choosing among five approaches (3rd ed.). USA: SAGE Publication.

Funk, K. (2001). What is worldview? Retrieved from http://web.engr.oregonstate.edu/ funkk/Personal/worldview.html

Furber, M. (2009). Ethics \& virtual worlds: Second life as a case study. In Tabah analytic brief. Abu Dhabi, U.A.E.: Tabah Foundation.

Gadalla, E., Abosag, I., and Keeling, K. (2016), "Second Life as a research environment: avatarbased focus groups (AFG)", Qualitative Market Research, Vol. 19 No. 1, pp. 101114. https://doi.org/10.1108/QMR-08-2015-0070

Holzwarth, M., Janiszewski, C., \& Neumann, M. M. (2006). The influence of avatars on online consumer shopping behaviour. Journal of Marketing, 70(4), 19-36.

Kamal, B. M., Ismael, S. A., \& Norhayati, M. Y. (2012). An exploratory study on the impact of virtual second life on the Islamic worldview of higher education student. IIUM Repository (IREP). http://irep.iium.edu.my/id/eprint/36414

Kozinets, R. V. (2010a). Netnography: The marketer's secret weapon: How social media understanding drives innovation. Retrieved from http://info.netbase.com/rs/netbase/images/netnography_wp.pdf

Kozinets, R. V. (2010b). Netnography: Doing ethnographic research online. London: SAGE Publications Ltd. 